\title{
Conformational changes in matrix-isolated 6-methoxyindole: Effects of the thermal and infrared light excitations
}

\author{
A. J. Lopes Jesus, ${ }^{1,2}$ I. Reva, ${ }^{1, a)}$ C. Araujo-Andrade, ${ }^{1,3,4}$ and R. Fausto ${ }^{1}$ \\ ${ }^{1}$ CQC, Department of Chemistry, University of Coimbra, 3004-535 Coimbra, Portugal \\ ${ }^{2}$ CQC, Faculty of Pharmacy, University of Coimbra, 3004-295 Coimbra, Portugal \\ ${ }^{3}$ Unidad Académica de Física de la Universidad Autónoma de Zacatecas, Zacatecas, Mexico \\ ${ }^{4}$ ICFO-The Institute of Photonic Sciences, 08860 Castelldefels (Barcelona), Spain
}

(Received 11 January 2016; accepted 7 March 2016; published online XX XX XXXX)

\begin{abstract}
Conformational changes induced thermally or upon infrared excitation of matrix-isolated 6-methoxyindole were investigated. Narrowband near-infrared excitation of the first overtone of the $\mathrm{N}-\mathrm{H}$ stretching vibration of each one of the two identified conformers is found to induce a selective large-scale conversion of the pumped conformer into the other one. This easily controllable bidirectional process consists in the intramolecular reorientation of the methoxy group and allowed a full assignment of the infrared spectra of the two conformers. Matrices with different conformational compositions prepared by narrow-band irradiations were subsequently used to investigate the effects of both thermal and broadband infrared excitations on the conformational mixtures. Particular attention is given to the influence of the matrix medium (Ar vs. Xe) and conformational effects of exposition of the sample to the spectrometer light source during the measurements. (C) 2016 AIP Publishing LLC. [http://dx.doi.org/10.1063/1.4944528]
\end{abstract}

\section{INTRODUCTION}

Isolating molecular species in low-temperature solid matrices of inert gases is nowadays a well-established experimental technique used to characterize and control the conformational population of isolated molecules. ${ }^{1-4}$ Two methodologies are commonly employed to alter the relative abundance of the trapped conformers: annealing of the sample $e^{5,6}$ or subjecting it to narrowband or broadband radiation of the IR or UV spectral regions. ${ }^{2,7-14}$ In the first case, the population of less stable forms is reduced in favour of the most stable ones, providing that the energy barriers for the isomerizations can be surmounted. In the second case, the conformational interconversions may occur in both directions, thus permitting population and stabilization of very high energy conformers, which otherwise would be rather difficult to be experimentally detected. ${ }^{4,14,15}$

Very recently, we have investigated the conformational changes in matrix-isolated 6-methoxyindole (6MOI) induced by narrowband near-IR (NIR) excitation. ${ }^{2}$ Using monochromatic laser radiation tuned at the frequency characteristic of the first $\mathrm{NH}$ stretching overtones of the two identified conformers (see their geometries in Figure 1), we were able to selectively shift the conformational composition in both directions. Especially relevant in this isomerization is the fact that the rotating methoxy fragment and the excited $\mathrm{NH}$ group stay remote from one another (both are separated by four covalent bonds). Such remote infraredinduced isomerizations were observed previously by ultrafast spectroscopy in the gas phase. ${ }^{16-20}$ In matrices, however,

\footnotetext{
a) Author to whom correspondence should be addressed. Electronic mail: reva@qui.uc.pt
}

vibrationally induced conformational manipulation of remote groups is still very uncommon. To the best of our knowledge, in such experimental conditions, the only remote conformational interconversion triggered by selective NIR excitation has been reported by Halasa et al., for the $\mathrm{S}-\mathrm{H}$ rotamerization in 2-thiocytosine induced by NIR selective excitation of the $\mathrm{NH}_{2}$ stretching overtone. ${ }^{21}$

In this work, we explore different strategies of modifying the conformational distribution of 6MOI isolated in lowtemperature argon and xenon matrices. Therefore, after identifying and characterizing the two conformers of the molecule by infrared spectroscopy, changes on their relative populations were induced by annealing, as well as by broadband and narrowband NIR/mid-IR irradiation. It is important to point out that up to date, most of the studies about conformational isomerizations resulting from NIR/mid-IR excitations of matrix-isolated molecules involved the rotation of light $\mathrm{OH}$ (more frequently observed) ${ }^{3,4,22,23}$ or SH groups. ${ }^{21}$ On the other hand, in previous studies of molecules with conformers differing from each other by rotation of bulky fragments (such as $\mathrm{OCH}_{3}$ or $\mathrm{OCOH}$ ), no isomerizations have been observed after subjecting the matrices to broadband or narrowband IR radiation. ${ }^{23-25}$

From a wider perspective, the results obtained in this work provide basic knowledge that can be used to understand local conformational features in many relevant methoxyindole-containing naturally occurring and synthetic biomolecules. ${ }^{26-30}$ Also, the possibility of controlling the conformational distribution of $6 \mathrm{MOI}$ in matrices opens a window for exploiting its conformer-specific reactivity in condensed media (as opposite to the gas phase). In addition, this work also demonstrates in a very clear way that exposition of a conformationally flexible sample to the broadband 


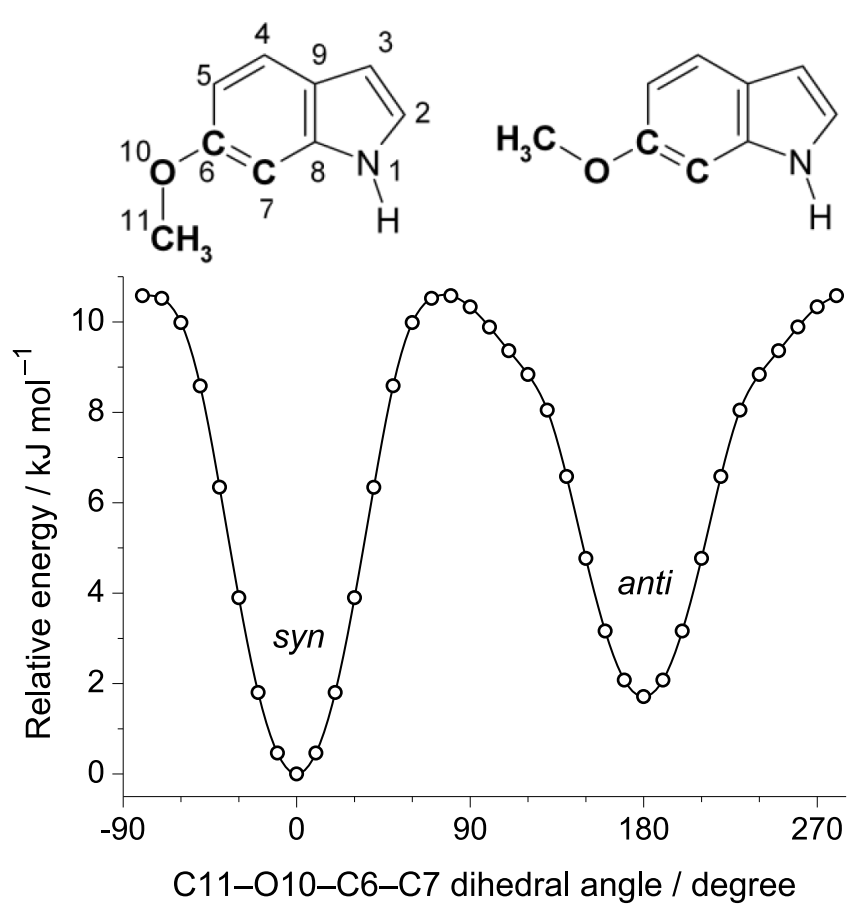

FIG. 1. Relaxed potential energy scan of 6MOI as function of the internal rotation of the $\mathrm{O}-\mathrm{CH}_{3}$ group calculated at the B3LYP/6-311++G(d,p) level of theory. The numbering scheme of heavy atoms is indicated for the most stable syn conformer, whose electronic energy was chosen as relative zero.

infrared beam of an infrared spectrometer might substantially influence the obtained results due to occurrence of $a$ priori unexpected IR-induced isomerization processes and also might be observed by stationary spectroscopic techniques.

\section{COMPUTATIONAL SECTION}

The minimum energy conformations of $6 \mathrm{MOI}$ were first identified through a potential energy scan, at the B3LYP/6$311++\mathrm{G}(\mathrm{d}, \mathrm{p})$ level of theory, around the C11-O10-C6-C7 dihedral angle, Figure 1. This dihedral was varied from 0 to $360^{\circ}$, with increments of $10^{\circ}$. At each scanning point, all the remaining internal coordinates were allowed to relax. The located minima were then fully optimized with the same B3LYP ${ }^{31-33}$ functional and the MP2 (second-order MøllerPlesset) method, ${ }^{34}$ both combined with the $6-311++G(d, p)$ and 6-311++G(3df,3pd) basis sets. The respective Cartesian coordinates are provided in Table S1 of the supplementary material. ${ }^{43}$ Harmonic B3LYP vibrational calculations were conducted on the geometries optimized at the same level. This allowed calculating the zero-point vibrational energy (ZPVE), as well as the thermal and entropic energy corrections, both evaluated at $323 \mathrm{~K}$ (temperature of the vapours of the compound before the matrix deposition, see below). Through these calculations, it was also possible to obtain the theoretical vibrational frequencies and infrared intensities that are listed in Table S2 of the supplementary material. ${ }^{43}$ To correct for the systematic shortcomings of the applied methodology (vibrational anharmonicity, basis set truncation, and the neglected part of electron correlation) and for the matrix shifts, two multiplicative factors were used to scale the calculated B3LYP/6-311++G(d,p) harmonic vibrational frequencies: 0.95 above $3300 \mathrm{~cm}^{-1}$ (for the $\mathrm{NH}$ stretching modes) and 0.98 below $3300 \mathrm{~cm}^{-1}$ (for the remaining modes). All quantum-mechanical computations referred above were carried out with the Gaussian 09 program package. ${ }^{35}$

\section{EXPERIMENTAL SECTION}

Commercial 6MOI, supplied by Apollo Scientific (98\% purity), has been used in the matrix isolation experiments. A few milligrams of the solid compound was placed inside a miniature glass oven which was then assembled inside the vacuum chamber of a cryostat, constituted by an APD cryogenics closed-cycle helium refrigerator system with a DE-202A expander. Argon and xenon matrices were prepared by co-deposition of vapors of the compound coming out from the oven (resistively heated up to $\sim 323 \mathrm{~K}$ ) with an excess of the host gas (argon N60 and xenon N48, both supplied by Air Liquide) onto a CsI optical substrate, which was cooled to 16 and $20 \mathrm{~K}$ during deposition of $6 \mathrm{MOI}$ into argon and xenon matrices, respectively. The temperature of the CsI window was measured directly at the sample holder with an accuracy of $0.1 \mathrm{~K}$ by using a silicon diode sensor connected to a digital controller (Scientific Instruments, Model 9650-1).

In order to monitor the deposition process and to follow the conformational changes occurring in the matrices, mid-infrared spectra $\left(4000-400 \mathrm{~cm}^{-1}\right)$ were collected using a Thermo Nicolet 6700 Fourier-transform infrared (FTIR) spectrometer equipped with a $\mathrm{Ge} / \mathrm{KBr}$ beam splitter and a mercury cadmium telluride (MCT-B) detector, cooled by liquid $\mathrm{N}_{2}$. All mid-IR spectra were collected with a resolution of $0.5 \mathrm{~cm}^{-1}$. In the near-infrared range, the spectra were recorded with a resolution of $1 \mathrm{~cm}^{-1}$, using a $\mathrm{CaF}_{2}$ beam splitter and the same MCT-B detector. Narrowband frequencytunable NIR light provided by the idler beam of a Quanta-Ray MOPO-SL optical parametric oscillator pumped with a pulsed $\mathrm{Nd}$ :YAG laser (pulse energy $10 \mathrm{~mJ}$, duration $10 \mathrm{~ns}$, repetition rate $10 \mathrm{~Hz}$ ), was used to irradiate the matrices. In some experiments, a standard Edmund Optics long-pass filter was used (transmission cutoff value of $\sim 4.50 \mu \mathrm{m}$ ) to protect the matrices from light with wavenumbers above $2200 \mathrm{~cm}^{-1}$.

\section{RESULTS AND DISCUSSION}

\section{A. Gas phase conformational equilibrium}

Two minimum energy conformations are identified from the potential energy scan displayed in Figure 1. Both have the heavy atoms of methoxy group lying in the same plane of the indole ring ( $C_{\mathrm{s}}$ symmetry). This maximizes the conjugation between the electron lone-pairs of the oxygen atom and the $\pi$-system of the aromatic ring. ${ }^{36}$ Following the nomenclature adopted by Brand et al.,${ }^{37}$ the conformer with $\alpha=0^{\circ}$ is designated as syn, while that with $\alpha=180^{\circ}$ is called anti. In the first case, the $\mathrm{OCH}_{3}$ and $\mathrm{NH}$ groups are pointing in the same direction, while in the second they are pointing in opposite directions. The geometries of both conformers are shown in Figure 1, while their relative electronic energies $\left(\Delta E_{\text {elec }}\right)$, 
TABLE I. Relative electronic $\left(\Delta E_{\text {elec }}\right)$, zero-point corrected $\left(\Delta E_{0}\right)$, and

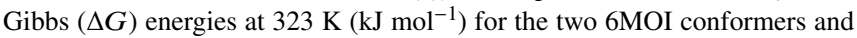
their Boltzmann populations estimated at the same temperature (pop., \%).

\begin{tabular}{lcc}
\hline \hline & \multicolumn{2}{c}{ Conformer } \\
\cline { 2 - 3 } Level of theory & Syn & anti \\
\hline B3LYP & & \\
$\Delta E_{\text {elec }}$ & $0.00 / 0.00$ & $1.78 / 1.93$ \\
$\Delta E_{0}$ & $0.00 / 0.00$ & $1.72 / 1.76$ \\
$\Delta G(323 \mathrm{~K})$ & $0.00 / 0.00$ & $1.14 / 1.20$ \\
Pop. $(323 \mathrm{~K})^{\mathrm{b}}$ & $60.4 / 61.0$ & $39.6 / 39.0$ \\
MP2 & & \\
$\Delta E_{\text {elec }}$ & $0.00 / 0.00$ & $3.17 / 2.90$ \\
$\Delta E_{0}$ & $0.00 / 0.00$ & $3.11 / 2.74$ \\
$\Delta G(323 \mathrm{~K})$ & $0.00 / 0.00$ & $2.53 / 2.18$ \\
Pop. $(323 \mathrm{~K})^{\mathrm{b}}$ & $72.0 / 69.2$ & $28.0 / 30.8$ \\
CC2/cc-p VTZ & & 3.23 \\
$\Delta E_{\text {elec }}$ & & 2.98 \\
$\Delta E_{0}$ & 0.00 & 24.8 \\
Pop. $(323 \mathrm{~K})^{\mathrm{e}}$ & 0.00 & \\
\hline \hline
\end{tabular}

${ }^{a}$ Values on the left hand-side of the slash were obtained with the $6-311++G(d, p)$ basis set, while those on the right hand-side were obtained with the $6-311++\mathrm{G}(3 \mathrm{df}, 3 \mathrm{pd})$ basis set.

${ }^{\mathrm{b}}$ Estimated from the Gibbs energy values.

${ }^{\mathrm{c}}$ The ZPVE as well as the thermal and entropic corrections at $323 \mathrm{~K}$ added to the MP2 electronic energies was calculated at the B3LYP level

${ }^{\mathrm{d}}$ Taken from Ref. 37.

${ }^{\mathrm{e}}$ Estimated from the relative zero-point corrected energies $\left(\Delta E_{0}\right)$.

zero-point corrected energies $\left(\Delta E_{0}, E_{0}=E_{\text {elec }}+\mathrm{ZPVE}\right)$, and Gibbs energies $(\Delta G)$ at $323 \mathrm{~K}$ (temperature of the gaseous samples prior to the matrix deposition), predicted at different levels of theory, are given in Table I. This table shows also the predicted Boltzmann populations of the two forms at $323 \mathrm{~K}$.

At the B3LYP level of theory, syn is the lowest energy conformer with anti being 1.8 or $1.9 \mathrm{~kJ} \mathrm{~mol}^{-1}$ higher in energy, depending on if this functional is combined with the $6-311++\mathrm{G}(\mathrm{d}, \mathrm{p})$ or $6-311++\mathrm{G}(3 \mathrm{df}, 3 \mathrm{pd})$ basis sets, respectively. Optimizations with the MP2 method do not alter the energetic order of the two conformers, though their energy difference increases to $\sim 3 \mathrm{~kJ} \mathrm{~mol}^{-1}$. This MP2 energy difference is very close to that computed with the approximate coupled cluster single and doubles model (CC2) combined with the cc-pVTZ basis set, $3.2 \mathrm{~kJ} \mathrm{~mol}^{-1} .{ }^{37}$ Adding the ZPVE, as well as the thermal and entropic corrections to the electronic energies, the Gibbs energy difference between the two forms at $323 \mathrm{~K}$ is reduced to $\sim 1.2 \mathrm{~kJ} \mathrm{~mol}^{-1}$ (DFT (density functional theory)) and to $2.2-2.5 \mathrm{~kJ} \mathrm{~mol}^{-1}$ (MP2). It follows that the predicted equilibrium abundances of the anti and syn forms at this temperature are, respectively, $\sim 60 \%$ : $\sim 40 \%$ at the DFT level and $\sim 70 \%$ : $\sim 30 \%$ at the MP2 level. Again, these values are similar to those obtained from the zero-point corrected CC2-energies. ${ }^{37}$

Based on these predictions, the two conformers should be present in the gaseous sample of 6MOI before the matrix deposition. Since they are separated by a medium-high energy barrier $\left(\sim 9 \mathrm{~kJ} \mathrm{~mol}^{-1}\right.$ in the anti $\rightarrow$ syn direction, see Figure 1$)$, no conformational cooling ${ }^{5,6,38,39}$ is expected to occur during the deposition, and therefore both of them should be preserved in both matrices immediately after the deposition, as it has already been confirmed in our previous experiments. ${ }^{2}$

\section{B. Interpretation of the mid-IR spectra}

Figure 2 shows the mid-infrared spectra of 6MOI isolated in an argon (Fig. 2(a)) and a xenon (Fig. 2(b)) matrix, measured immediately after the matrix deposition. We shall call them for brevity "Ar spectrum" and "Xe spectrum" hereafter. Approximate descriptions of the vibrations assigned to the experimental bands are presented in Table II.

At a glance, there is no appreciable difference between both experimental spectra. The only notable exception is the profile of the spectral feature located at the $3550-3450 \mathrm{~cm}^{-1}$ interval, which is assigned to the stretching vibration of the $\mathrm{NH}$ group $(v \mathrm{NH})$. For $6 \mathrm{MOI}$ in xenon matrix, this absorption has a doublet profile with two well-defined components at 3498 and $3494 \mathrm{~cm}^{-1}$. In the case of the argon matrix, this band is split into seven sub-bands, with the most prominent ones located
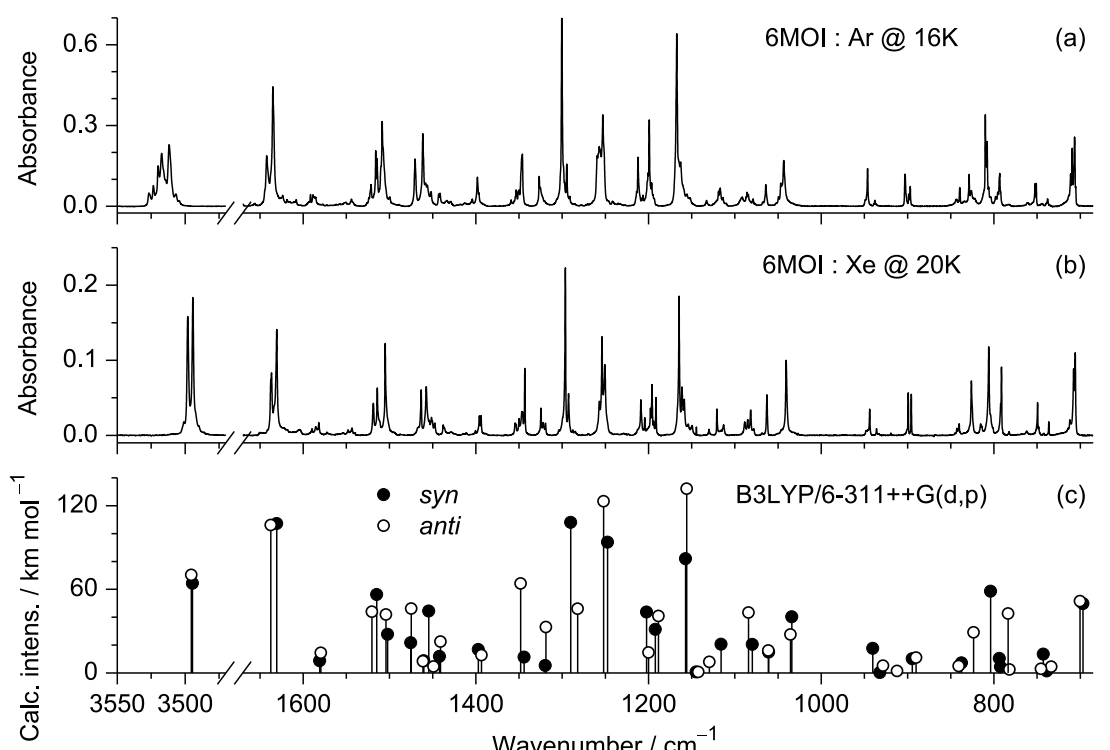

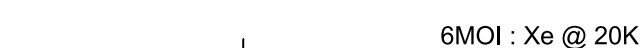

(b)

FIG. 2. Experimental mid-IR spectra recorded immediately after deposition of 6MOI in low-temperature $\mathrm{Ar}$ (a) and $\mathrm{Xe}$ (b) matrices, and (c) theoretical spectra of the syn (closed circles) and anti (open circles) conformers calculated at the $\mathrm{B} 3 \mathrm{LYP} / 6$ $311++G(d, p)$ level of theory. The computed wavenumbers above and below $3300 \mathrm{~cm}^{-1}$ were multiplied by 0.95 and 0.98 , respectively. 
TABLE II. Experimental and calculated [B3LYP/6-311++G(d,p)] wavenumbers $\left(\tilde{v}, \mathrm{~cm}^{-1}\right)$ and calculated infrared intensities $\left(\mathrm{I}, \mathrm{km} \mathrm{mol}^{-1}\right)$ for the isolated 6MOI molecule.

\begin{tabular}{|c|c|c|c|c|c|c|c|}
\hline & & \multicolumn{4}{|c|}{ Calculated $^{\mathrm{b}}$} & \multirow[b]{3}{*}{ Sym. } & \multirow[b]{3}{*}{ Approximate description ${ }^{\mathrm{c}}$} \\
\hline \multicolumn{2}{|c|}{ Experimental $^{\mathrm{a}}$} & \multicolumn{2}{|c|}{ syn } & \multicolumn{2}{|c|}{ anti } & & \\
\hline $\mathrm{Xe}, 20 \mathrm{~K}$ & Ar, $16 \mathrm{~K}$ & $\tilde{v}$ & I & $\tilde{v}$ & I & & \\
\hline $3498(s)^{d}$ & $3512(\mathrm{~m})$ & & & 3491.8 & 70.4 & $\mathrm{~A}^{\prime}$ & $v \mathrm{NH}$ \\
\hline $3494(v s)^{d}$ & $\begin{array}{l}3520 / 3517(\mathrm{w}) \\
3507(\mathrm{vw})\end{array}$ & 3490.9 & 64.3 & & & $\mathrm{~A}^{\prime}$ & $v \mathrm{NH}$ \\
\hline $1637(w)^{d}$ & $1642(w)^{d}$ & & & 1637.5 & 106.1 & $\mathrm{~A}^{\prime}$ & $v \mathrm{CC}_{\text {benz }}$ \\
\hline $1631(s)^{d}$ & $1635(\mathrm{~s})^{\mathrm{d}}$ & 1630.5 & 107.1 & & & $\mathrm{~A}^{\prime}$ & $v \mathrm{CC}_{\text {benz }}$ \\
\hline $1519(w)^{d}$ & $1521(\mathrm{vw})^{\mathrm{d}}$ & & & 1520.4 & 43.9 & $\mathrm{~A}^{\prime}$ & $v \mathrm{C} 2 \mathrm{C} 3$ \\
\hline $1514(w)^{d}$ & $1516^{*}(w)^{d}$ & 1514.9 & 56.2 & & & $\mathrm{~A}^{\prime}$ & $v \mathrm{C} 2 \mathrm{C} 3$ \\
\hline $1505(\mathrm{~s})$ & $1508(\mathrm{~m})$ & 1502.2 & 27.7 & 1504.1 & 42.0 & $\mathrm{~A}^{\prime}$ & $\delta \mathrm{C} 5 \mathrm{H}+\delta \mathrm{NH}+v \mathrm{CC}$ \\
\hline $1463(\mathrm{~m})$ & $1470(w)$ & 1475.4 & 21.6 & 1474.9 & 46.2 & $\mathrm{~A}^{\prime}$ & $\delta \mathrm{CH}_{3}$ as \\
\hline $1457(w)$ & $1462(w)$ & 1454.2 & 44.4 & & & $\mathrm{~A}^{\prime}$ & $\delta \mathrm{C} 4 \mathrm{H}+\delta \mathrm{C} 7 \mathrm{H}+\mathrm{C} 2 \mathrm{H}$ \\
\hline 1437 (vw) & $1442(\mathrm{vw})$ & 1442.1 & 11.8 & 1440.9 & 22.4 & $\mathrm{~A}^{\prime}$ & $\delta \mathrm{CH}_{3} \mathrm{~s}$ \\
\hline $1396(\mathrm{vw})$ & $1398(\mathrm{vw})$ & 1397.0 & 16.9 & & & $\mathrm{~A}^{\prime}$ & $\nu \mathrm{C} 2 \mathrm{~N}+\delta \mathrm{NH}+\delta \mathrm{CH}_{\mathrm{py}}$ \\
\hline $1394(\mathrm{vw})$ & $1396(\mathrm{vw})$ & & & 1393.5 & 12.8 & $\mathrm{~A}^{\prime}$ & $\nu \mathrm{C} 2 \mathrm{~N}+\delta \mathrm{NH}+\delta \mathrm{CH}_{\mathrm{py}}$ \\
\hline $1343 *(\mathrm{~m})$ & $1346 *(w)$ & 1344.1 & 11.3 & 1348.2 & 64.2 & $\mathrm{~A}^{\prime}$ & $\delta \mathrm{C} 5 \mathrm{H}+\delta \mathrm{NH}$ \\
\hline $1325^{*}(\mathrm{w})$ & $1327(\mathrm{vw})$ & 1319.6 & 5.3 & 1318.9 & 32.9 & $\mathrm{~A}^{\prime}$ & $\delta \mathrm{CH}+v \mathrm{CC}$ \\
\hline $1296(v s)^{d}$ & $1300(\mathrm{vs})^{\mathrm{d}}$ & 1290.2 & 108.0 & & & $\mathrm{~A}^{\prime}$ & $v \mathrm{C} 6 \mathrm{O}+v \mathrm{C} 8 \mathrm{~N}+v \mathrm{CC}$ \\
\hline $1293(w)^{d}$ & $1295(w)^{d}$ & & & 1282.1 & 46.1 & $\mathrm{~A}^{\prime}$ & $v \mathrm{C} 6 \mathrm{O}+v \mathrm{C} 8 \mathrm{~N}+v \mathrm{CC}$ \\
\hline $1254 *(\mathrm{~s})$ & $1257(\mathrm{~m})$ & & & 1252.1 & 123.1 & $\mathrm{~A}^{\prime}$ & $\delta \mathrm{CH}$ \\
\hline $1251(\mathrm{~m})$ & $1253(\mathrm{~m})$ & 1247.5 & 93.8 & & & $\mathrm{~A}^{\prime}$ & $\delta \mathrm{CH}$ \\
\hline $1209 / 1204(w)$ & $1212(w)$ & 1202.3 & 43.7 & 1199.9 & 14.6 & $\mathrm{~A}^{\prime}$ & $\delta \mathrm{CH}$ \\
\hline $1196 / 1191(w)$ & $1199(\mathrm{~m})$ & 1192.1 & 31.2 & 1188.5 & 40.9 & $\mathrm{~A}^{\prime}$ & $\rho \mathrm{CH}_{3}$ \\
\hline $1165^{*}(\mathrm{vs})$ & 1167 (vs) & 1157.2 & 82.0 & 1155.8 & 132.2 & $\mathrm{~A}^{\prime}$ & $\rho \mathrm{CH}_{3}+\delta \mathrm{C} 7 \mathrm{H}+\delta \mathrm{NH}$ \\
\hline $1130(\mathrm{vw})$ & $1133(\mathrm{vw})$ & & & 1129.6 & 7.9 & $\mathrm{~A}^{\prime}$ & $\delta \mathrm{C} 4 \mathrm{H}+\delta \mathrm{C} 5 \mathrm{H}$ \\
\hline $1121 / 1113(\mathrm{vw})$ & $1117 *(\mathrm{vw})$ & 1115.9 & 20.6 & & & $\mathrm{~A}^{\prime}$ & $\delta \mathrm{C} 4 \mathrm{H}+\delta \mathrm{C} 5 \mathrm{H}$ \\
\hline $1082 *(w)$ & $1086^{*}(\mathrm{vw})$ & 1079.8 & 20.5 & 1084.1 & 43.3 & $\mathrm{~A}^{\prime}$ & $\delta \mathrm{C} 2 \mathrm{H}$ \\
\hline $1063(w)$ & $1064(\mathrm{vw})$ & 1060.8 & 14.9 & 1061.3 & 16.1 & $\mathrm{~A}^{\prime}$ & $\delta \mathrm{C} 3 \mathrm{H}$ \\
\hline $1041(\mathrm{~m})$ & $1043 *(w)$ & 1034.0 & 40.3 & 1035.6 & 27.6 & $\mathrm{~A}^{\prime}$ & $v \mathrm{C} 11 \mathrm{O}+\delta \mathrm{C} 7 \mathrm{H}$ \\
\hline 944 (vw) & $946(w)$ & 940.3 & 17.6 & & & $\mathrm{~A}^{\prime}$ & $\delta$ benz \\
\hline $936(\mathrm{vw})$ & $938(\mathrm{vw})$ & & & 928.4 & 5.2 & $\mathrm{~A}^{\prime}$ & $\delta$ benz \\
\hline $899(w)^{d}$ & $903(w)^{d}$ & 894.6 & 10.2 & & & $\mathrm{~A}^{\prime}$ & $\delta$ py \\
\hline $896(w)^{d}$ & $897 *(\mathrm{vw})^{\mathrm{d}}$ & & & 890.2 & 11.0 & $\mathrm{~A}^{\prime}$ & $\delta$ py \\
\hline 843 (vw) & $844(\mathrm{vw})$ & & & 840.8 & 5.0 & $\mathrm{~A}^{\prime \prime}$ & $\gamma \mathrm{C} 2 \mathrm{H}+\gamma \mathrm{C} 3 \mathrm{H}$ iop \\
\hline $840(\mathrm{vw})$ & 839 (vw) & 837.5 & 7.3 & & & $\mathrm{~A}^{\prime \prime}$ & $\gamma \mathrm{C} 2 \mathrm{H}+\gamma \mathrm{C} 3 \mathrm{H}$ iop \\
\hline $826(w)$ & $829(w)$ & & & 823.5 & 29.1 & $\mathrm{~A}^{\prime \prime}$ & $\gamma \mathrm{C} 7 \mathrm{H}$ \\
\hline $806(\mathrm{~m})^{\mathrm{d}}$ & $810^{*}(\mathrm{~m})^{\mathrm{d}}$ & 803.8 & 58.6 & & & $\mathrm{~A}^{\prime \prime}$ & $\gamma \mathrm{C} 4 \mathrm{H}+\gamma \mathrm{C} 5 \mathrm{H}$ isp \\
\hline $791(s)^{d}$ & $793(w)^{d}$ & & & 783.7 & 42.6 & $\mathrm{~A}^{\prime \prime}$ & $\gamma \mathrm{C} 4 \mathrm{H}+\gamma \mathrm{C} 5 \mathrm{H}$ isp \\
\hline $749 *(\mathrm{vw})$ & $752 *(\mathrm{vw})$ & 742.7 & 13.4 & 745.4 & 3.0 & $\mathrm{~A}^{\prime \prime}$ & $\gamma$ ind \\
\hline 737 (vw) & $738(\mathrm{vw})$ & & & 733.6 & 4.5 & $\mathrm{~A}^{\prime}$ & $\delta$ benz \\
\hline 712/708 (m) & $711 / 709(w)$ & 696.8 & 49.8 & & & $\mathrm{~A}^{\prime \prime}$ & $\gamma \mathrm{C} 2 \mathrm{H}+\gamma \mathrm{C} 3 \mathrm{H}$ isp \\
\hline $706(\mathrm{~m})$ & $707 *(\mathrm{~m})$ & & & 700.3 & 51.5 & $\mathrm{~A}^{\prime \prime}$ & $\gamma \mathrm{C} 2 \mathrm{H}+\gamma \mathrm{C} 3 \mathrm{H}$ isp \\
\hline
\end{tabular}

${ }^{\mathrm{a} E x p e r i m e n t a l}$ intensities are expressed in a qualitative way: $\mathrm{vs}=$ very strong; $\mathrm{s}=$ strong; $\mathrm{m}=\mathrm{medium}$; $\mathrm{w}=\mathrm{weak} ; \mathrm{vw}=\mathrm{very}$ weak. Some of the absorptions with very low intensity, as well as those falling in the $3150-2800 \mathrm{~cm}^{-1}$ region $\left(\mathrm{CH}^{2}\right.$ and $\mathrm{CH}_{3}$ stretching vibrations) and below $700 \mathrm{~cm}^{-1}$ are not shown. For some split bands (denoted by an asterisk), only the most intense components are shown.

${ }^{\mathrm{b}}$ Calculated harmonic wavenumbers are scaled by 0.95 and 0.98 , above and below $3300 \mathrm{~cm}^{-1}$, respectively. The assignment of the experimental absorptions to a specific conformer was based on the direct comparison between the calculated and experimental bands and on the spectral changes induced by the thermal and NIR excitations.

${ }^{c}$ Carried out by ChemCraft animation of the vibrations of the syn and anti conformers. Abbreviations: $v$, stretching; $\delta$, in-plane deformation; $\gamma$, out-of-plane deformation; $\rho$, rocking; s, symmetric; as, antisymmetric; isp, in the same phase; iop, in the opposite phase; ind, indole ring; py, pyrrole fragment; benz, benzene fragment.

${ }^{\mathrm{d}}$ Pairs of bands used to estimate the conformational populations.

near 3512, 3517, and $3520 \mathrm{~cm}^{-1}$ (see Figure 3(b) for details). Since 6MOI possesses only two conformers that could be stabilized in the solid matrices, and each of them gives rise to only one transition in this spectral range (NH stretching), the more complex pattern exhibited by this absorption in the $\operatorname{Ar} 319$ spectrum must be due to the existence of different trapping 320 sites in this matrix host, which gives rise to a number of ${ }_{321}$ closely located IR peaks. An attempt to assign these trapping 322 

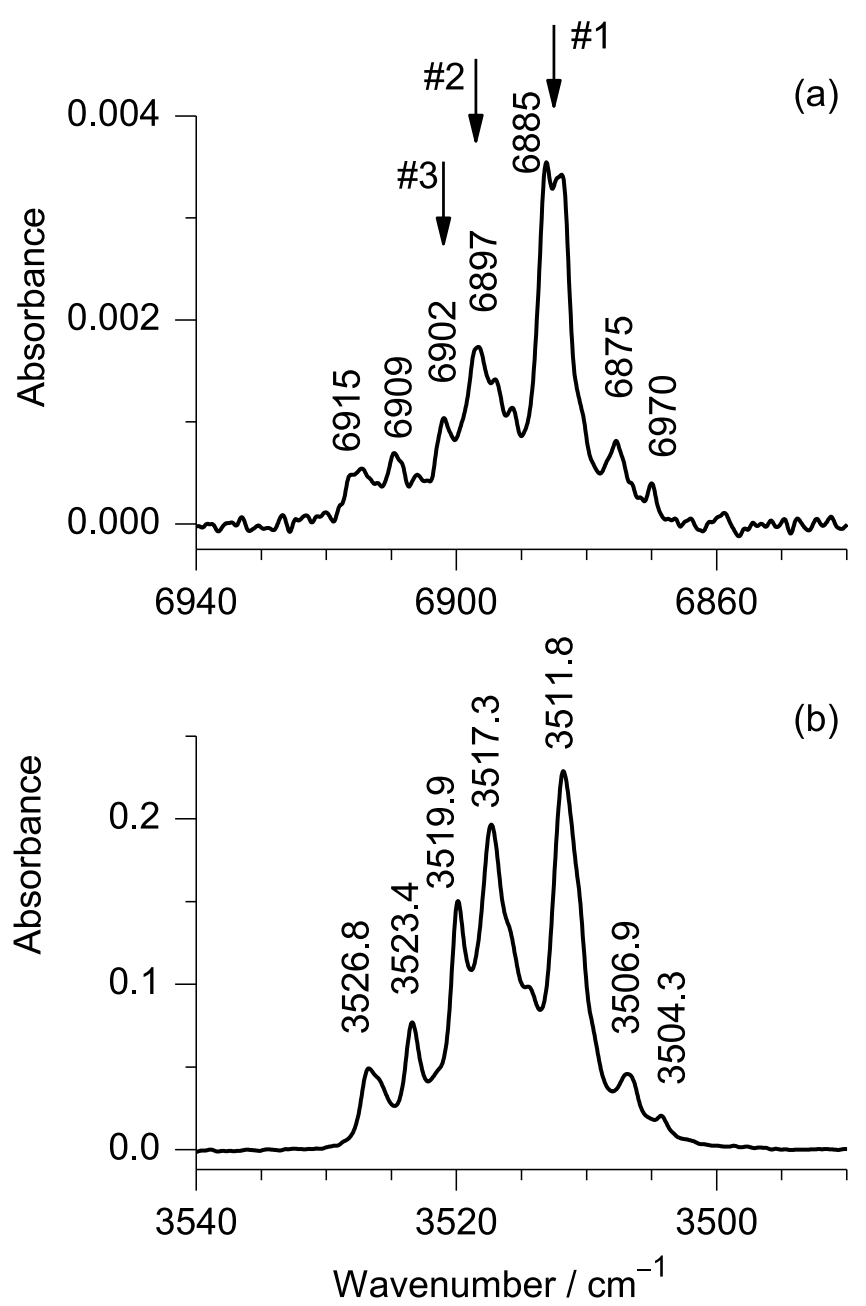

FIG. 3. Fragments of the near-IR (a) and mid-IR (b) spectrum of 6MOI isolated in solid argon at $16 \mathrm{~K}$ showing the multiplet profiles of the absorption bands due to the $2 v \mathrm{NH}$ overtone transition and $v \mathrm{NH}$ fundamental transition. The numbered vertical arrows show the positions of the near-IR irradiations, whose effects are depicted in Figure 4.

sites to different conformers is described below, where the results of the monochromatic NIR irradiations were taken into account.

Comparing now the mid-IR experimental spectra with those calculated for the two conformers (Figure 2(c)), it becomes evident that both forms are stabilized in the matrix. As a matter of fact, some of the doublets found in the experimental spectra, such as those located in the 3498-3494 $\mathrm{cm}^{-1}\left(v \mathrm{NH}\right.$, only in Xe), 1645-1630 $\mathrm{cm}^{-1}$ (vCC $\left.{ }_{\text {benz }}\right), 1521-1514$ (vC2C3), 1300-1293 $\mathrm{cm}^{-1}$ (vC6O $+v \mathrm{C} 8 \mathrm{~N}+v \mathrm{CC}), 1257-1251 \mathrm{~cm}^{-1}(\delta \mathrm{CH}), 903-896 \mathrm{~cm}^{-1}\left(\delta_{\mathrm{py}}\right)$ regions, correspond, in the calculated spectra, to pairs of vibrations of both conformers. In the $840-780 \mathrm{~cm}^{-1}$ region, it is also possible for discriminating band characteristic of both conformers. Indeed, those at $826(\mathrm{Xe}) / 829(\mathrm{Ar}) \mathrm{cm}^{-1}(\gamma \mathrm{C} 7 \mathrm{H})$ and $791 / 793 \mathrm{~cm}^{-1}(\gamma \mathrm{C} 4 \mathrm{H}+\gamma \mathrm{C} 5 \mathrm{H}$ isp $)$ are with no doubt assigned to the less stable conformer, while the middle one centred at $806 / 810 \mathrm{~cm}^{-1}(\gamma \mathrm{C} 4 \mathrm{H}+\gamma \mathrm{C} 5 \mathrm{H}$ iop $)$ corresponds to the most stable form. Based on this comparison and on the spectral modifications observed upon annealing and NIR irradiations (see discussion below), ${ }^{2}$ some of the experimental bands can be reliably assigned to a specific conformer, as shown in Table II.

In quantitative terms, the populations $(P)$ of the two matrix-isolated conformers can be estimated from the integrated absorbances $(A)$ of different doublet bands, each one of the components assigned to a different conformer, normalized by the corresponding calculated intensities $(I)$ : $P_{\text {syn }} / P_{\text {anti }}=\left(A_{\text {syn }} / A_{\text {anti }}\right) \times\left(I_{\text {anti }} / I_{\text {syn }}\right)$. Six pairs of bands of the Xe spectrum and five of the Ar spectrum, which are indicated in Table II, were used to estimate the populations. The following mean values ( \pm standard deviation) were obtained: Xe, $P_{\text {syn }} / P_{\text {anti }}=1.5 \pm 0.2(59 \%: 41 \%) ; \quad$ Ar, $\quad P_{\text {syn }} / P_{\text {anti }}=2.0$ $\pm 0.1(67 \%: 33 \%)$. It is worth noticing that according to these estimations, the conformational composition in solid xenon is more shifted towards the less stable rotamer than in argon. In addition, it is also interesting to see that the results obtained in argon are close to the MP2-predicted gas-phase populations, while those found in xenon are in excellent agreement with the B3LYP predictions. The above population ratio of $6 \mathrm{MOI}$ conformers observed in xenon matrix results from a fortuitous coincidence with the B3LYP prediction. The true reasons can be understood by a deep analysis of the photo- and thermally induced isomerizations occurring in both matrices, as described in detail below.

\section{Narrowband near-IR excitations}

As referred in the Introduction, we have previously demonstrated that the two conformers of 6MOI can be converted into one another by exposing the matrix to monochromatic NIR laser-light tuned at the frequency of the respective first $\mathrm{NH}$ stretching overtone $(2 v \mathrm{NH}){ }^{2}$ In the case of the Xe matrix, these $2 v \mathrm{NH}$ absorptions have been identified at 6855.6 and $6849.3 \mathrm{~cm}^{-1}$ for the anti and syn conformers, respectively, with the $v \mathrm{NH}$ counterparts at 3498.0 and $3494.5 \mathrm{~cm}^{-1}$ in the fundamental region. A large-scale $s y n \rightarrow$ anti transformation was detected upon irradiation at $6849 \mathrm{~cm}^{-1}$, while the reverse process could be also induced by tuning the laser light at $6856 \mathrm{~cm}^{-1}$.

Concerning the spectrum recorded in Ar matrix, the multiplet profile of the $2 v \mathrm{NH}$ (Figure $3(\mathrm{a})$ ) and $v \mathrm{NH}$ (Figure 3(b)) absorptions requires a more careful analysis in order to assign the band components in these regions to a specific conformer. NIR excitations were carried out at wavenumbers corresponding to different maxima within the $2 v \mathrm{NH}$ profile. Their positions are designated by numbered vertical arrows in Figure 3(a). The outcome of these irradiations was monitored through the spectral variations occurring in the $3530-3500 \mathrm{~cm}^{-1}$ and $1650-1625 \mathrm{~cm}^{-1}$ midIR regions, Figure 4. The latter region is shown as a reference, because it contains a doublet band where the higher and lower frequency components are unequivocally assigned to the anti and syn conformers, respectively (see Table II).

The NIR irradiations were initiated by tuning the laser at the position of the most intense $2 v \mathrm{NH}$ peak: $6885 \mathrm{~cm}^{-1}$ (see arrow \#1 in Fig. 3(a)). The intensity variations observed in the doublet band at $1642 / 1635 \mathrm{~cm}^{-1}$ (Fig. 4(b), right), as well as in the other pairs of bands in the mid-IR range, unmistakably reveal the existence of an anti $\rightarrow$ syn conversion. Based on this 

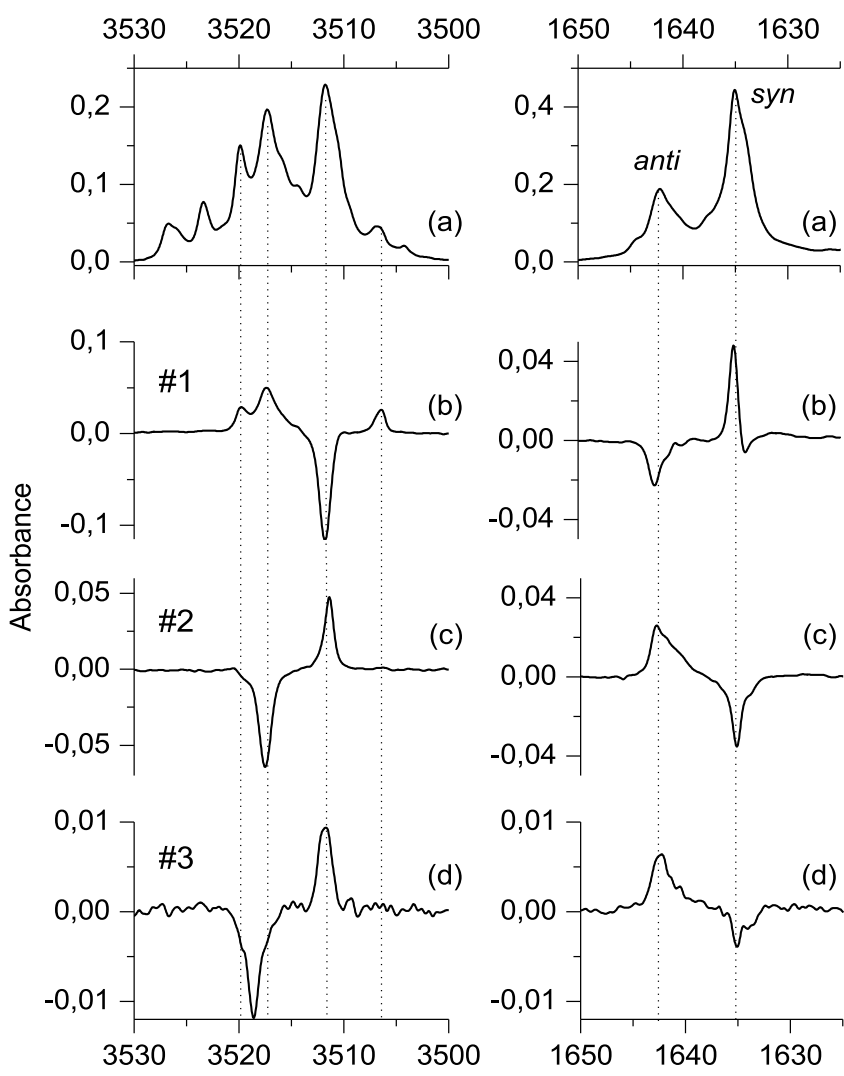

(c)

Wavenumber $/ \mathrm{cm}^{-1}$

FIG. 4. Representation of the $3530-3500 \mathrm{~cm}^{-1}$ ((a), left) and 1650-1625 $\mathrm{cm}^{-1}$ ((a), right) regions of the mid-IR spectrum of 6MOI isolated in solid argon at $16 \mathrm{~K}$, and spectral changes in these regions after narrowband NIR irradiations \#1 at $6885 \mathrm{~cm}^{-1}$ (b), \#2 at $6897 \mathrm{~cm}^{-1}$ (c), and \#3 at $6902 \mathrm{~cm}^{-1}$ (d) (see Figure 3). These changes are shown in frames ((b)-(d)) and correspond to difference spectra obtained by subtracting the spectrum recorded after the irradiation from that measured before the irradiation. Positive bands in frames ((b)-(d)) correspond to those growing up during the irradiations.

result, one can assign the most intense $v \mathrm{NH}$ band component located near $3512 \mathrm{~cm}^{-1}$ to the anti conformer and those near 3520,3517 , and $3506 \mathrm{~cm}^{-1}$ (which grow up under these experimental conditions) to the syn conformer trapped into three different matrix sites. ${ }^{40}$ The next irradiation was carried out at $6897 \mathrm{~cm}^{-1}$ (arrow \#2 in Fig. 3(a)) and led to the opposite conformational conversion (Fig. 4(c)). Note that in this case, only the syn conformers trapped into the most populated site (identified by the peak near $3517 \mathrm{~cm}^{-1}$ ) were converted to anti, while those trapped into the less abundant sites (identified by the peaks near 3520 and $3506 \mathrm{~cm}^{-1}$, Fig. 3(b)) remained unchanged. A similar syn $\rightarrow$ anti transformation (Fig. 4(d)), though much less effective, was induced by a NIR excitation at $6902 \mathrm{~cm}^{-1}$ (arrow \#3 in Fig. 3(a)). In an attempt to excite the conformers trapped into the sites responsible for the peaks near 3527 and $3523 \mathrm{~cm}^{-1}$, we have conducted excitations at the corresponding overtones: 6915 and $6909 \mathrm{~cm}^{-1}$ (see the highest-frequency components in Figures 3(a) and 3(b)). However, no significant spectral changes were detected, which was taken as an indication that the molecules trapped in these sites are not reactive.

\section{Thermal annealing}

Previous matrix-isolation conformational studies have been performed in methoxy-group-containing molecules with conformers differing from each other by rotation of the $\mathrm{OCH}_{3}$ group and separated by energy barriers higher than $8 \mathrm{~kJ}$ $\mathrm{mol}^{-1} \cdot{ }^{24,25,41}$ In all cases, no conformational relaxation was observed upon annealing the argon matrices up to the limit for the thermal stability of the host-material ( $\sim 35 \mathrm{~K})$. Conformational conversions were only observed after depositing some of these molecules (i.e., those with accessible energy barriers for conformational isomerization) in xenon and heating the matrices up to temperatures ranging from 30 to $55 \mathrm{~K}(\sim 65$ $\mathrm{K}$ is the limit for this host matrix). Based on these results, the annealing experiments in 6MOI were only conducted in xenon.

After co-deposition of $6 \mathrm{MOI}$ with a solid xenon host at $20 \mathrm{~K}$, we have exposed the matrix-isolated compound to the monochromatic radiation of $6849 \mathrm{~cm}^{-1}$ in order to enrich the sample with the less stable anti conformer, which is expected to be consumed upon annealing. After that, the solid sample
421 422 423 424 425 426 427 428 429 430 431 432 433 434 435 436 437 
was gradually heated with increments of $2 \mathrm{~K}$. When the sample temperature reached $34 \mathrm{~K}$, the intensity of the bands assigned to the anti conformer started to decrease, and concomitantly the bands ascribed to the syn form increased. These spectral changes became more pronounced after additional heating to $38 \mathrm{~K}$ and occurred on the time scale of a few minutes. This is well-evidenced in Figure 5, which compares selected spectral regions measured at $38 \mathrm{~K}$ and $30 \mathrm{~K}$ (a difference spectrum in the full mid-IR region is shown in Figure S1 of the supplementary material ${ }^{43}$ ). These results provide irrefutable evidence for the existence of an anti $\rightarrow$ syn relaxation, thus confirming that syn is in fact the most stable rotamer. In an attempt to produce the maximum possible amount of this form, we have proceeded with annealing up to $50 \mathrm{~K}$. Under these conditions, it could be expected that the populations of the two conformers would shift towards those characteristic of the $50 \mathrm{~K}$ conformational equilibrium: $P_{\text {syn }}>97 \% ; P_{\text {anti }}<3 \%$, values estimated from the Boltzmann distributions of the DFT and MP2 zero-point corrected energies (see Table I). In practical terms, this means that at this temperature, the less stable anti form should be entirely depopulated. However, despite the statistical prediction, such an equilibrium state was not achieved: the most prominent absorptions characteristic of the anti form were found to persist in the IR spectra measured at $50 \mathrm{~K}$ with a non-negligible intensity (even after letting the sample at this temperature for tens of minutes). Using the integrated intensity of the two peaks observed at 899 and $896 \mathrm{~cm}^{-1}$, which are assigned to the in-plane deformation of the pyrrole ring for the anti and syn conformers, respectively, the abundance of the less stable anti form at $50 \mathrm{~K}$ was found to be $\sim 25 \%$ (a similar estimation was obtained from other doublets). As this value is well above the predicted equilibrium population at $50 \mathrm{~K}$, it can be concluded that something is shifting the conformational composition away from the equilibrium one, i.e., in the direction opposite from that triggered by temperature.

\section{E. Effect of the broadband radiation emitted by the spectrometer source}

With the objective of following the effect responsible for the non-establishment of a thermodynamic equilibrium in the Xe matrix, the annealed sample was cooled down to $30 \mathrm{~K}$ (in order to minimize the thermal effects) and kept at this temperature for about $2 \mathrm{~h}$. During this period, various mid-IR spectra were recorded at regular time intervals. The variation of the intensity of the $899 / 896 \mathrm{~cm}^{-1}$ pair of bands shown in Figure 6(a) undoubtedly demonstrates that the most stable syn conformer is converted back into the less stable anti form. Quantitatively, after $2 \mathrm{~h}$, the abundance of the anti conformer increased from $25 \%$ to $44 \%$, while that of syn decreased from $75 \%$ to $56 \%$, as illustrated in Figure 6(b). Interestingly, the final conformational composition (44\%:56\%) is very similar to that estimated from the integration of the same pair of bands in the spectrum collected immediately after the deposition of the xenon matrix at $20 \mathrm{~K}$, as mentioned at the end of Section IV B. This result suggests that the conformational ratio is also affected during the matrix deposition. After keeping the sample at $30 \mathrm{~K}$ for two additional hours and
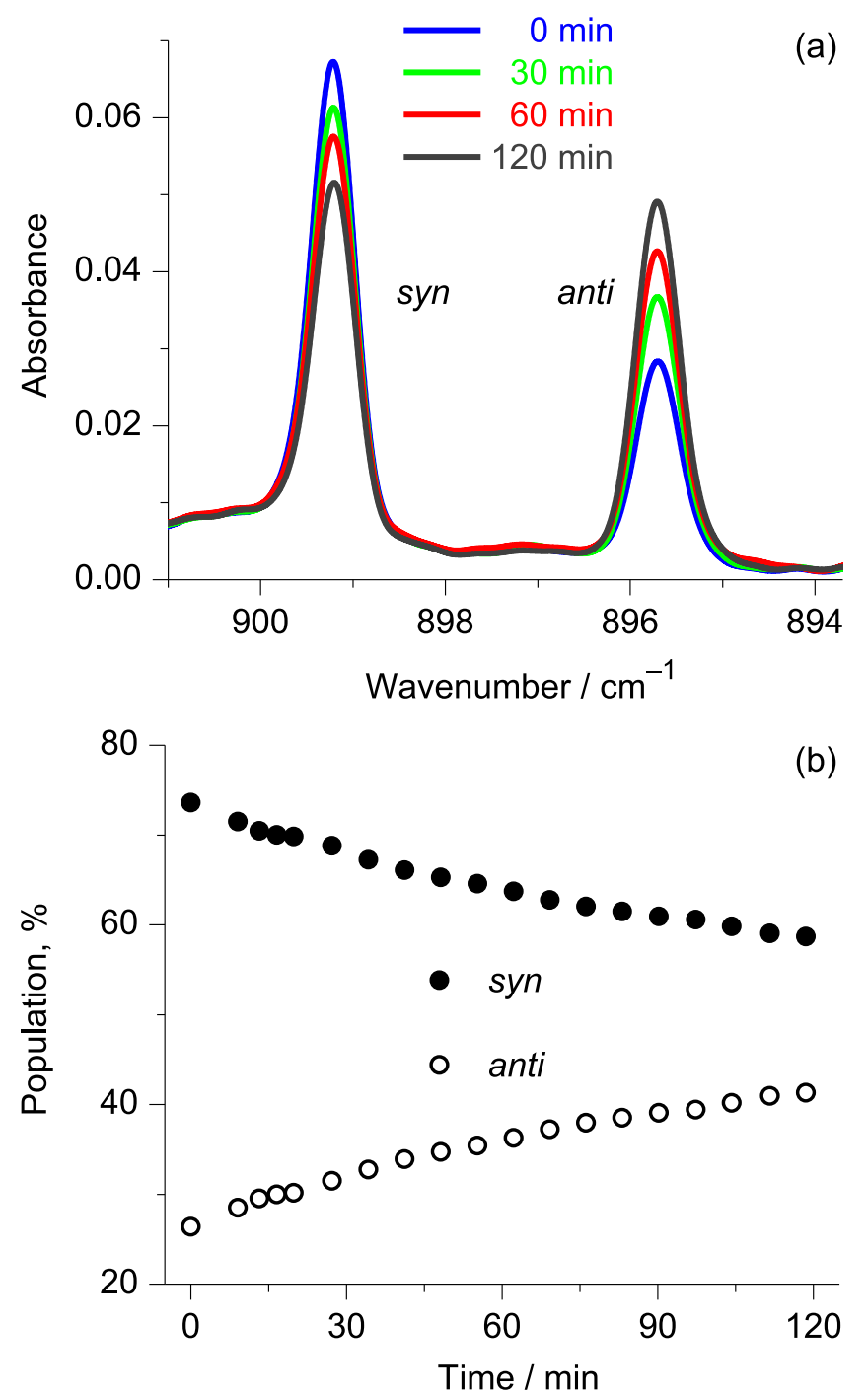

FIG. 6. (a) Intensity change of the pair of bands located in the $900-895 \mathrm{~cm}^{-1} \quad 515$ spectral range during the permanence of $6 \mathrm{MOI}$ in a xenon matrix at $30 \mathrm{~K}$ for $2 \mathrm{~h}$, after annealing the sample up to $50 \mathrm{~K}$ and cooling it back to $30 \mathrm{~K}$; (b) variation of the population of the two conformers (obtained from the integrated intensities of the two bands) as a function of time. The initial time corresponds to the moment at which the sample was cooled back to $30 \mathrm{~K}$. During recording of the spectra, the sample was exposed to the unfiltered light of the spectrometer source.

recording various spectra at the end of this period, no further changes in the populations of both conformers were detected (see Figure S2 of the supplementary material ${ }^{43}$ ), meaning that the conformational composition reached a stationary state. This was characterized by approximately equal amounts of the two forms: $51 \%$ (syn):49\% (anti).

In order to verify if this effect also works in the anti $\rightarrow$ syn direction, we have irradiated, once again, the matrix with NIR laser-light tuned at $6849 \mathrm{~cm}^{-1}$ in order to increase the concentration of the less stable anti form up to $73 \%$, and let the sample for about half-an-hour at $30 \mathrm{~K}$, periodically recording its mid-IR spectra. This resulted in a consumption of the less stable form, thus proving the bidirectional nature of this phenomenon.

The isothermal syn $\leftrightarrow$ anti interconversion observed in the xenon matrix is most likely originated by the 


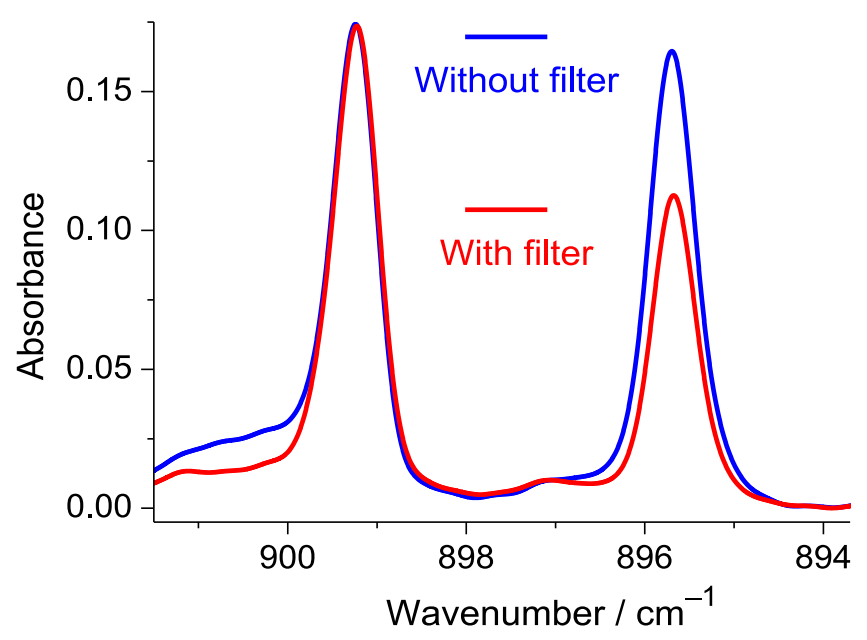

FIG. 7. Fragment of the spectrum of $6 \mathrm{MOI}$ isolated in a xenon matrix at $30 \mathrm{~K}$, recorded immediately after deposition, in the presence of a filter transmitting only infrared light with wavenumbers below $2100 \mathrm{~cm}^{-1}$ (red) and in the absence of this filter (blue). The two spectra were normalized to the same peak intensity of the higher frequency band of the syn form.

NIR/mid-IR broadband radiation emitted from the source of the spectrometer, a type of photoeffect that has already been observed for systems differing by a flip of the $\mathrm{OH}$ group. ${ }^{10,42}$ To confirm this, we have conducted another experiment in which the conformational composition of 6MOI in the xenon matrix during deposition was monitored by collecting only a part of IR spectrum. For this purpose, we used a cutoff IR filter placed between the spectrometer source and the matrix that blocks the sample from the IR light above $2200 \mathrm{~cm}^{-1}$. This prevents the absorption by the molecule of energies higher than $26 \mathrm{~kJ} \mathrm{~mol}^{-1}$. Figure 7 shows the spectral variations in the $899 / 896 \mathrm{~cm}^{-1}$ doublet resulting from the introduction of the filter. Clearly, the $A_{\text {syn }} / A_{\text {anti }}$ ratio is much higher in the sample monitored with the presence of the filter than in the sample monitored without the filter. In quantitative terms and considering the contribution of all selected doublets, the abundances (mean values) of the two conformers in the matrix not exposed to the higher energy IR radiation emitted by the spectrometer source are estimated to be $P_{\text {syn }} \sim 68 \%: P_{\text {anti }} \sim 32 \%$.

From these results the following remarks can be made: (1) The broadband mid-IR radiation emitted by the spectrometer source is responsible for the interconversion between the two conformers in the xenon matrix at $30 \mathrm{~K}$; (2) this effect shifts the conformational distribution towards a photostationary state characterized by nearly equal amounts of the two forms (on the time scale of hours); (3) the conformational distribution estimated after deposition of the xenon matrix with the filter is very close to the predicted MP2 gas-phase populations, thus indicating that the energy difference between the two conformers is predicted accurately enough by this theoretical method.

With the aim of checking whether the broadband IR radiation also affects the conformational distribution when the compound is isolated in solid argon, an additional experiment was performed. The matrix deposition, carried out at $16 \mathrm{~K}$, was monitored by collecting spectra in the presence of the IR filter, which was removed upon completing deposition.
Interestingly, after about $9 \mathrm{~h}$ of leaving the sample in the spectrometer beam, the recorded mid-IR spectrum was found to be practically coincident with that measured before removing the filter (see Figure S3 of the supplementary material $^{43}$ ). Hence, contrarily to xenon, no conformational isomerization takes place in the argon matrix exposed to unfiltered radiation, difference that we attribute to the more tight trapping cages in the argon crystal lattice as compared to xenon. The abundances of the two conformers trapped in this host matrix $\left(P_{\text {syn }} \sim 67 \%: P_{\text {anti }} \sim 33 \%\right)$ are equal to those estimated from the xenon spectra measured with the presence of the filter and to the MP2 gas-phase populations.

\section{CONCLUSIONS}

Conformational changes induced thermally or upon infrared excitation of matrix-isolated 6-methoxyindole were investigated. Narrowband infrared excitation of the first overtone of the N-H stretching vibration of each one of the two conformers (syn; anti) of the molecule induces the selective large-scale conversion of the pumped conformer into the other one. This allowed the full assignment of the infrared spectra of the conformers and to prepare matrices with different conformational compositions, which were subsequently used to investigate the effects of both thermal and broadband infrared excitations upon the conformational mixtures.

The results were substantially different in argon and xenon matrices:

- When argon is used as matrix medium, the gas phase conformational equilibrium prior to matrix preparation can be efficiently trapped in the matrix: for the used temperature of the 6MOI gas phase, $323 \mathrm{~K}$, a syn:anti population ratio of about 2:1 was measured, matching well to the MP2 predicted population ratio at that temperature. Due to tight trapping cages in the argon solid lattice as compared to xenon, no conformational isomerization takes place in the argon matrix exposed to unfiltered broadband infrared radiation of the spectrometer beam.

- On the other hand, when xenon is used as host medium, the conformational composition existing in the gas phase can only be efficiently trapped in the matrix when the higher-energy infrared light $\left(>2200 \mathrm{~cm}^{-1}\right)$ of the spectrometer beam is blocked during the experiments. Exposition of the sample to the unfiltered spectrometer infrared beam leads to IR-induced conformational interconversion. For a xenon matrix kept below the temperature at which the thermally induced anti $\rightarrow$ syn conversion becomes accessible $(\sim 35 \mathrm{~K})$, prolonged exposition to the unfiltered spectrometer infrared beam leads to the attainment of a photostationary state with a population ratio of about $1: 1$, independently of the initial conformational composition of $6 \mathrm{MOI}$ in the matrix.

The effect of the unfiltered spectrometer infrared beam on the 6MOI conformational mixture also justifies the impossibility to completely depopulate the higher-energy anti 
conformer upon annealing (at $50 \mathrm{~K}$ ) of the xenon matrix of the compound exposed to the unfiltered spectrometer infrared beam during spectra collection. The different population ratio (about 1.5:1), measured immediately after deposition of the xenon matrix, compared to that observed both in case of the argon matrix and xenon matrix kept protected from radiation with $\lambda>2200 \mathrm{~cm}^{-1}$, implies a partial anti $\rightarrow$ syn conversion, induced by the spectrometer light source.

Finally, it is important to emphasize that 6MOI, to the best of our knowledge, is the unique case where the isomerization of a heavy-atom fragment (methoxy group) takes place by the action of broad-band infrared and near-infrared light in a rigid matrix, in contrast to previous studies where electronic ground-state light-induced isomerizations were only related with the flip of light $\mathrm{OH}$ or $\mathrm{SH}$ groups.

\section{ACKNOWLEDGMENTS}

This work was supported by the Portuguese "Fundação para a Ciência e a Tecnologia" (FCT). The Coimbra Chemistry Centre is supported by the FCT through the Project No. PestOE/QUI/UI0313/2014. I.R. acknowledges FCT for the Investigador FCT grant.

${ }^{1}$ R. Fausto, L. Khriachtchev, and P. Hamm, in Physics and Chemistry at Low Temperatures, edited by L. Khriachtchev (Pan Stanford, Singapore, 2011), p. 51.

${ }^{2}$ A. J. Lopes Jesus, I. Reva, C. Araujo-Andrade, and R. Fausto, J. Am. Chem. Soc. 137, 14240 (2015).

${ }^{3}$ A. Sharma, I. Reva, and R. Fausto, J. Am. Chem. Soc. 131, 8752 (2009).

${ }^{4}$ M. Pettersson, J. Lundell, L. Khriachtchev, and M. Räsänen, J. Am. Chem. Soc. 119, 11715 (1997)

${ }^{5}$ I. D. Reva, A. J. Lopes Jesus, M. T. S. Rosado, R. Fausto, M. Ermelinda Eusebio, and J. S. Redinha, Phys. Chem. Chem. Phys. 8, 5339 (2006).

${ }^{6}$ M. T. S. Rosado, A. J. Lopes Jesus, I. D. Reva, R. Fausto, and J. S. Redinha, J. Phys. Chem. A 113, 7499 (2009).

${ }^{7}$ I. D. Reva, S. Jarmelo, L. Lapinski, and R. Fausto, J. Phys. Chem. A 108, 6982 (2004).

${ }^{8}$ G. Bazsó, E. E. Najbauer, G. Magyarfalvi, and G. Tarczay, J. Phys. Chem. A 117, 1952 (2013).

${ }^{9}$ N. Akai, S. Kudoh, M. Takayanagi, and M. Nakata, J. Phys. Chem. A 106, 11029 (2002).

${ }^{10}$ L. Lapinski, I. Reva, H. Rostkowska, R. Fausto, and M. J. Nowak, J. Phys. Chem. B 118, 2831 (2014).

${ }^{11}$ E. E. Najbauer, G. Bazsó, S. Góbi, G. Magyarfalvi, and G. Tarczay, J. Phys. Chem. B 118, 2093 (2014).

${ }^{12}$ S. Coussan, Y. Bouteiller, J. P. Perchard, and W. Q. Zheng, J. Phys. Chem. A 102, 5789 (1998).

${ }^{13}$ S. Nishino and M. Nakata, J. Phys. Chem. A 111, 7041 (2007).

${ }^{14}$ D. Gerbig and P. R. Schreiner, J. Phys. Chem. B 119, 693 (2015).

${ }^{15}$ I. Reva, C. M. Nunes, M. Biczysko, and R. Fausto, J. Phys. Chem. A 119, 2614 (2015).

${ }^{16}$ C. Seaiby, A. V. Zabuga, A. Svendsen, and T. R. Rizzo, J. Chem. Phys. 144, 014304 (2016).

${ }^{17}$ T. R. Rizzo, J. A. Stearns, and O. V. Boyarkin, Int. Rev. Phys. Chem. 28, 481 (2009).

${ }^{18}$ B. C. Dian, A. Longarte, and T. S. Zwier, J. Chem. Phys. 118, 2696 (2003).
${ }^{19}$ B. C. Dian, A. Longarte, P. R. Winter, and T. S. Zwier, J. Chem. Phys. 120 133 (2004).

${ }^{20}$ B. C. Dian, J. R. Clarkson, and T. S. Zwier, Science 303, 1169 (2004).

${ }^{21}$ A. Halasa, L. Lapinski, H. Rostkowska, and M. J. Nowak, J. Phys. Chem. A 119, 9262 (2015).

${ }^{22}$ C. M. Nunes, L. Lapinski, R. Fausto, and I. Reva, J. Chem. Phys. 138, 125101 (2013).

${ }^{23}$ A. Halasa, L. Lapinski, I. Reva, H. Rostkowska, R. Fausto, and M. J. Nowak, J. Phys. Chem. A 119, 1037 (2015).

${ }^{24}$ N. Kuş, A. Sharma, I. Reva, L. Lapinski, and R. Fausto, J. Phys. Chem. A 114, 7716 (2010).

${ }^{25}$ S. Breda, I. Reva, L. Lapinski, and R. Fausto, J. Phys. Chem. A 110, 11034 (2006).

${ }^{26}$ N. Kaushik, N. Kaushik, P. Attri, N. Kumar, C. Kim, A. Verma, and E. Choi, Molecules 18, 6620 (2013).

${ }^{27}$ R. Vicente, Org. Biomol. Chem. 9, 6469 (2011).

${ }^{28}$ A. J. Kochanowska-Karamyan and M. T. Hamann, Chem. Rev. 110, 4489 (2010).

${ }^{29}$ S. Mahboobi, H. Pongratz, H. Hufsky, J. Hockemeyer, M. Frieser, A. Lyssenko, D. H. Paper, J. Bürgermeister, F.-D. Böhmer, H.-H. Fiebig, A. M. Burger, S. Baasner, and T. Beckers, J. Med. Chem. 44, 4535 (2001).

${ }^{30}$ G. Tarzia, G. Diamantini, B. Di Giacomo, G. Spadoni, D. Esposti, R. Nonno, V. Lucini, M. Pannacci, F. Fraschini, and B. M. Stankov, J. Med. Chem. 40, 2003 (1997).

${ }^{31}$ A. D. Becke, Phys. Rev. A 38, 3098 (1988).

${ }^{32}$ C. T. Lee, W. T. Yang, and R. G. Parr, Phys. Rev. B 37, 785 (1988).

${ }^{33}$ S. H. Vosko, L. Wilk, and M. Nusair, Can. J. Phys. 58, 1200 (1980)

${ }^{34}$ C. Møller and M. S. Plesset, Phys. Rev. 46, 618 (1934).

${ }^{35}$ M. J. Frisch, G. W. Trucks, H. B. Schlegel, G. E. Scuseria, M. A. Robb, J. R. Cheeseman, G. Scalmani, V. Barone, B. Mennucci, G. A. Petersson, H. Nakatsuji, M. Caricato, X. Li, H. P. Hratchian, A. F. Izmaylov, J. Bloino, G. Zheng, J. L. Sonnenberg, M. E. M. Hada, K. Toyota, R. Fukuda, J. Hasegawa, M. Ishida, T. Nakajima, Y. Honda, O. Kitao, H. Nakai, T. Vreven, J. A. Montgomery, Jr., J. E. Peralta, F. Ogliaro, M. Bearpark, J. J. Heyd, E. Brothers, K. N. Kudin, V. N. Staroverov, R. Kobayashi, J. Normand, K. Raghavachari, A. Rendell, J. C. Burant, S. S. Iyengar, J. Tomasi, M. Cossi, N. Rega, J. M. Millam, M. Klene, J. E. Knox, J. B. Cross, V. Bakken, C. Adamo, J. Jaramillo, R. Gomperts, R. E. Stratmann, O. Yazyev, A. J. Austin, R. Cammi, C. Pomelli, J. W. Ochterski, R. L. Martin, K. Morokuma, V. G. Zakrzewski, G. A. Voth, P. Salvador, J. J. Dannenberg, S. Dapprich, A. D. Daniels, Ö. Farkas, J. B. Foresman, J. V. Ortiz, J. Cioslowski, and D. J. Fox, GaUsSian 09, Revision D.01, Gaussian, Inc., Wallingford, CT, 2009.

${ }^{36}$ A. J. Lopes Jesus and J. S. Redinha, Struct. Chem. 26, 655 (2015).

${ }^{37}$ C. Brand, O. Oeltermann, M. Wilke, and M. Schmitt, J. Chem. Phys. 138, 024321 (2013).

${ }^{38}$ P. Felder and H. H. Günthard, Chem. Phys. 71, 9 (1982).

${ }^{39}$ A. J. Barnes, J. Mol. Struct. 113, 161 (1984).

${ }^{40}$ It should be noted that the theoretically predicted frequencies of the $\mathrm{NH}$ stretching mode coincide within one wavenumber (see Table II). The ordering of these peaks appearing in the experiments depends on fine interactions between the isolated $6 \mathrm{MOI}$ monomers and the matrix host gas. In a Xe matrix, the NH stretching band assigned to the most stable form appears at a slightly higher frequency relative to the absorption assigned to the less stable conformer. In an argon matrix, the guest:host interactions are similar for both conformers, and combined with manifestations of different matrix sites, the respective absorption components of the anti and syn forms appear interlaced.

${ }^{41}$ I. Reva, A. Simão, and R. Fausto, Chem. Phys. Lett. 406, 126 (2005).

${ }^{42}$ I. Reva, M. J. Nowak, L. Lapinski, and R. Fausto, J. Chem. Phys. 136, 064511 (2012).

${ }^{43}$ See supplementary material at http://dx.doi.org/10.1063/1.4944528 for optimized Cartesian coordinates and calculated infrared spectra of the two $6 \mathrm{MOI}$ conformers, as well as for the changes in spectra of matrix-isolated $6 \mathrm{MOI}$ after annealing and absence of changes in the spectra upon long exposure to the spectrometer light source. 